\title{
Transformation of the accountancy profession during digitalization of agriculture
}

\author{
Galina Bakulina ${ }^{2}$, Galina Kalinina ${ }^{1}$, Inna Luchkova, ${ }^{2, *}$, Maria Pikushina $^{2}$, and Alla Gracheva ${ }^{1}$ \\ ${ }^{1}$ Academy of the FRS of Russia, 390000 Ryazan, Russia \\ ${ }^{2}$ Ryazan State Agrotechnological University named after P.A. Kostychev, 390044 Ryazan, Russia
}

\begin{abstract}
The article is devoted to the changes in the profession of accountant and accounting in the process of digitalization of the agricultural economy. The concept of digitalization of the economy is revealed, its directions in the agricultural sector are determined. The necessity of creating a single information space of an agricultural enterprise that promotes the interaction of structural units is considered. The priority role of accounting in the formation of the information base and in the creation of an analytical platform for the digitalization of the agro-industrial complex is highlighted. The robotic system as a tool of the digital economy is presented. The stages of accounting robotization are revealed: organizational and informational, robotic data processing, reporting and analytical, account management. The characteristic of each stage is given. A scheme of the movement of information in a robotic accounting system is proposed. The prerequisites for accounting robots that have developed in the current period and are necessary for future formation are outlined. The transformation of the profession of an accountant in the digital economy into an account manager is defined and its role in the digitalization of agriculture is highlighted.
\end{abstract}

\section{Introduction}

The modern economy determines promising directions of development through digitalization, which was fixed at the legislative level through the adoption of the national program "Digital Economy of the Russian Federation" [1].

According to the opinion of Khalina V.G. and Chernova G.V. digitalization in the narrow sense is the conversion of information into digital form, which in most cases leads to lower costs, the emergence of new opportunities, etc. and in a broad sense, it can be seen as a trend in the effective global development of digital transformation of information that meets the requirements of production, business, science, the social sphere and the ordinary life of citizens. Digitalization is accompanied by the effective use of its results, which are available to users of the converted information. Not only specialists, but also ordinary citizens use its results. Users of digital information have the skills to work with it. Thus, digitalization is a synergistic economy, which is not just the sum of the properties of its elements, but inherent only in the system as a whole with an integrated approach to managing the state and an individual enterprise [2].

The main elements of digitalization of agriculture are defined in the Federal scientific and technical program for the development of agriculture for 2017-2025 [3]. The main directions of digitalization of agriculture are as follows:
- creation of a digital base for decision support systems in the agricultural sector;

- digitalization of production, including robotization of technology and the introduction of elements of artificial intelligence;

- digitalization of sales of agricultural products;

- organization of analytical platforms across all verticals of the agro-industrial complex

\section{Results and discussion}

The priority condition for the formation of the analytical platform is a developed information base of the enterprise, the main source of which is the accounting system, including financial, tax and management accounting.

The development of accounting at the present stage tends to minimize the labour costs of an accountant and maximize information technology in the processing and transmission of data. Agriculture is a sector with a very intensive data flow requiring the creation of secure transmission systems. The organization of a single information space of an agricultural enterprise promotes the interaction of structural divisions: crop production, animal husbandry, mechanization, the administrative sector, and digitalization of production, accounting, management and decision-making [4]. In this combination, accounting plays the role of an information accumulator, being the foundation for digitalization of savings.

\footnotetext{
*Corresponding author: innaluchkova@ mail.ru
} 
The importance of accounting in agriculture is so far in many enterprises comes down to the need defined by law and is associated with reporting [5]. Young qualified personnel prefer employment in fast-growing, technologically advanced enterprises with a high level of wages. All this makes it difficult to introduce modern accounting information technologies in agriculture, and makes it impossible to take advantage of them.

The possibility and necessity of obtaining timely information for making managerial decisions In the changing market conditions dominates. Therefore, in addition to generating mandatory accounting and tax reports and declarations, the accounting information system should have a wide range of management reports. Since their composition and content are individual for each organization and leader, a lot will depend on the qualifications of the chief accountant and programmer.

The industry standard for accounting work at the Russian market is 1C: Enterprise system programs. Its decisions in the field of agriculture affect the automation of management processes and accounting. Automation of accounting is directly related to computerization, which contributes to the transition from manual and mechanized labor to the use of special applications, which makes possible to transfer some of the functions of accounting from a person to technology.

Accounting, technical operations related to settlement work, in their complexity and mass, occupy up to $75 \%$ of all work. Accounting is the collection of information on the property and liabilities of the organization, the reflection of operations performed with them and generalization in various reporting forms.

The work of an accountant in the past and in the future will differ significantly from the modern work of an accounting specialist, which is primarily associated with the development of modern equipment and technology. At present, the classification of the stages of development of accounting based on its technical and technological components is most relevant:

Stage 1 - traditional manual accounting;

Stage 2 - mechanized accounting;

Stage 3 - automated accounting;

Stage 4 - robotic accounting;

Stage 5 - accounting with the help of artificial intelligence.

Conventional accounting involves manual accounting. Under the mechanization one should understand the transition from manual work to using some mechanical tools. Automation involves the transfer of part of the functions of manual or mechanized work to automatic execution. With robotization, human labor is replaced by robot labor. The introduction of artificial intelligence will contribute to the self-development of a system focused on the possibility of autonomous decision-making taking into account changing initial conditions.

The history of accounting is rooted in ancient times, where accounting was carried out using clay and stone tablets, colorful pebbles. Recordings were made by drawings, hieroglyphs, using cuneiform writing, etc. The impetus for the development of accounting was the books of Benedetto Cotrulla "On Trade and the Modern
Merchant" (1458) and Luca Pacioli "On Accounts and Records" (1494), which revealed a double entry accounting system [3].

At the end of the $19^{\text {th }}$ century, the appearance of perforators, tabulators and arithmometers contributed to the mechanization of accounting work. As a result of the implementation of calculating devices, labor productivity was increased due to such operations as summation, multiplication, division, and grouping of credentials. The mechanization of accounting increased the accuracy and reliability of accounting parameters, the productivity of accounting employees and helped to establish uniform forms of accounting documents. Partial or complex mechanization was carried out depending on the type of computer technology and the degree of its availability. The latter contributed to the development of accounting automation.

The automation of accounting is directly related to computerization, which contributes to the transition from manual, mechanized labor to the use of special applications, which allowed some of the functions of accounting to be transferred from a person to technology. Automation of accounting has a strong influence on the functions of an accountant, who carries out registration of primary documents in an automated accounting system, performs analytical and control functions, while there is no need to perform routine mathematical operations, fill in documents and journals.

This makes possible to make the work of the accountant more interesting, passing ordinary routine operations to the machine. However, the need for a structure of qualified personnel is changing: accountants are leaving the labor market. There is an increasing need for programmers who are setting up universal programs to fit the particular organization, operators who enter the primary information and universal accountants who implement the control and operational management functions. The role of the chief accountant in the conditions of automated accounting at the modern level of automation remains relevant due to the imperfection of accounting information systems that require monitoring, and sometimes correction of results.

The transition to automated accounting systems requires a computer and software that meets the specifics of the enterprise and the organization of the accounting service.

The introduction of modern data processing and transmission technologies into the accounting service promotes bring a new stage in the development of accounting for robotics closer. At the same time, the accounting postulates formulated by Luca Pacioli: double entry, general ledger and others remain unchanged [6]. It is the conservatism of accounting that contributes to the development and implementation of its automation with the prospect of using intelligent robotics.

The formation of robotic accounting systems is a tool of the digital economy. The most significant technology contributing to the approximation of accounting robots is the technology associated with the use of modern bot applications, including a bot accountant who calculates insurance premiums, taxes, etc., a bot consultant that 
provides information support, as well as technologies that bring robotization closer to accounting, and these are: electronic signature, electronic document management, blockchains, etc. [7].

The transition to robotization involves a qualitatively new approach to organizing and maintaining accounting. The main stages of the robotic form of accounting will be:

1. organizational and informational;

2. robotic data processing;

3. reporting and analytical;

4. account management.

The organizational and informational stage involves the receipt of external and internal data in a robotic accounting system, as a result of which a base of primary documents is formed. External information will come from external sources and will require only confirmation, partial confirmation or refutation to be included in the accounting data of the organization. For example, information on the received materials from suppliers will be entered on the basis of documents that will be received by organizations on telecommunication systems.

Thus, upon confirmation of the supply of materials, seeds or feed, information will automatically be entered into the organization's accounting system data. If the volume or quality of the supplied materials, seeds or feed does not correspond to the documents received, then, depending on the decision made, a document on the noncompliance of the delivery will be generated and sent to the counterparty, etc.

The input of information generated within the organization will be carried out at the places of its occurrence directly by the heads of units or other responsible persons. For example, the supply of materials to plant growing and animal husbandry divisions from the warehouse by storekeepers or the use of materials in production by foremen in crop production and farm managers in animal husbandry. Therefore, the input of primary data will be reflected in the robotic information system at the time of completion of business operations and the result will be the formation of primary documents.

The second stage involves robotic processing of source information without human intervention. The stage of robotic data processing is characterized by the minimization of human intervention in the operation of the information robotic system. The internal algorithm of accounting operations and agricultural production processes in a robotic system is determined by a number of documents, which include: industry regulations and legislative acts.

The implementation of robotics will be carried out in two directions: process and integrated ones. Process robotization digitalizes individual agricultural processes or a set of interrelated processes, eliminating the possibility of human exposure to them. With complex robotization, the information flows of the individual processes of crop production, animal husbandry, mechanization, the administrative and management sector are linked through an accounting system that provides input of primary data, their processing and reporting.

The third stage summarizes the output information in a set of reporting and analytical forms. The result of data processing is the formation of various accounting registers, production reports of crop and livestock production, financial and management reporting, the use of which is possible within the enterprise and by external users.

At the fourth stage, the accounting information is used by the account manager as part of the management decisions made. At the stage of account management, the process of collecting, processing and analyzing data on the work of the organization is managed: their comparison with baseline and planned parameters, the results of activities of other organizations in order to timely identify problems, open reserves and ensure full use of existing potential [8].

This stage for the agricultural enterprises is the most eventful and responsible, as it redefines the functions of an accountant. Accounting robotization contributes to the redistribution of working hours from traditional accounting work in favor of developing, evaluating and making management decisions, while the information system generates a set of internal reports containing not only relevant information, but also the results of an interactive situation analysis, ensuring the effectiveness of daily work.

The flow of information in a robotic accounting system is shown in Figure 1.

It should be noted that prerequisites for accounting robotization have already been created. However, today these are only the first steps that require deep study and implementation. Table 1 summarizes the prerequisites for accounting robotization in the current period.

The development of accounting entails a change in attitude towards the profession of an accountant. The need for an accountant-bookkeeper has begun to disappear even with the mechanization of accounting and is now completely replaced by an accountantoperator, entering primary data into the information system [9].

This situation causes antipodal opinions to the future of the profession of an accountant [10]. For the first time, the position of this profession was shaken with the automation of accounting, when a computer and automated accounting systems took over the calculation work and technical operations. 


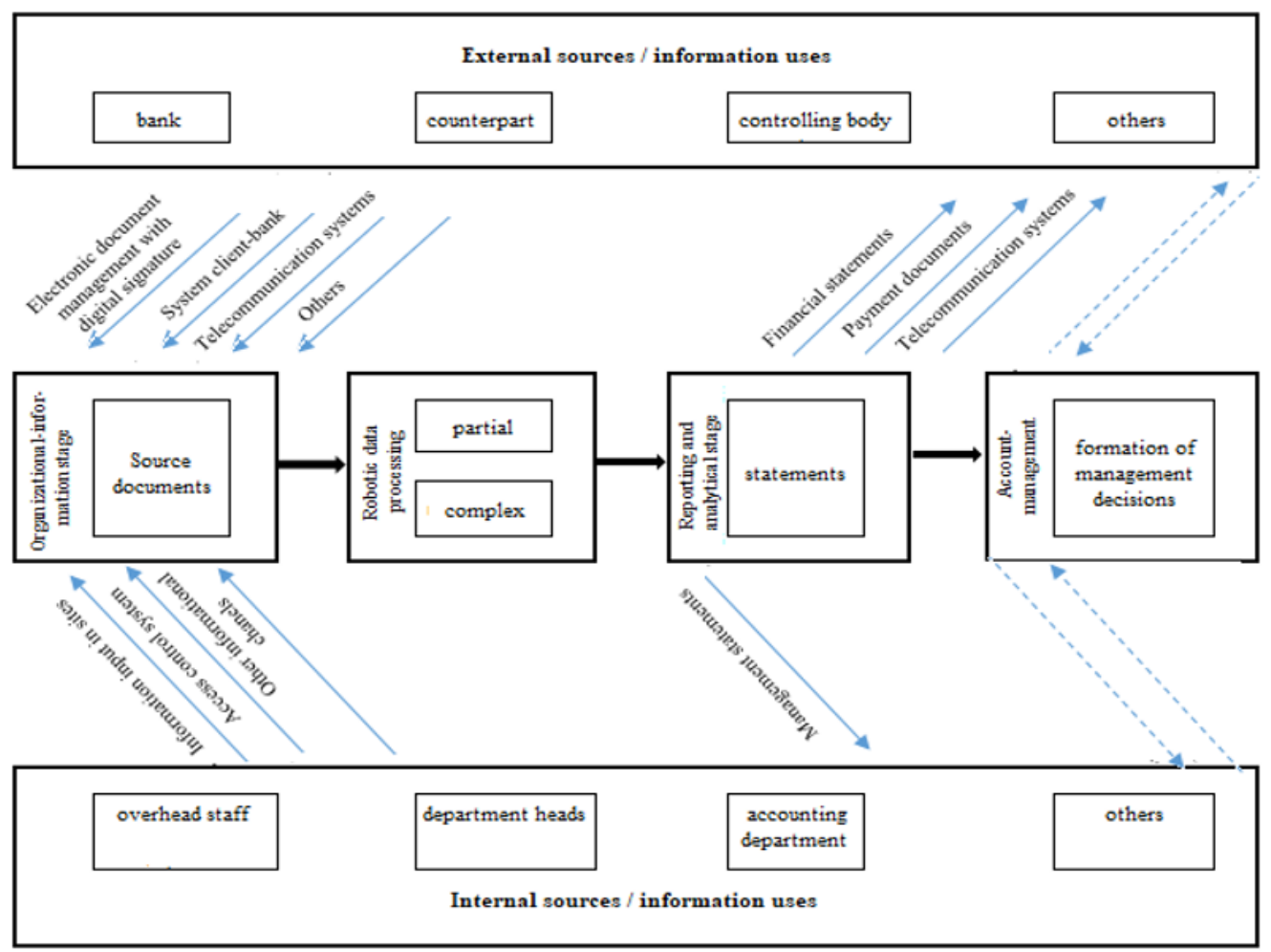

Fig. 1. Flow of information in a robotic accounting system

Table 1. Accounting robotization background

\begin{tabular}{|l|l|l|}
\hline \multicolumn{1}{|c|}{$\begin{array}{c}\text { Stages of a robotic } \\
\text { accounting form }\end{array}$} & $\begin{array}{l}\text { Preconditions for accounting robotization in } \\
\text { the current period }\end{array}$ & $\begin{array}{c}\text { Prerequisites for accounting robotization necessary } \\
\text { for future formation }\end{array}$ \\
\hline Organizational information & $\begin{array}{l}\text { electronic document management, } \\
\text { including Client-Bank, Kontur External, } \\
\text { SBIS, etc. }\end{array}$ & $\begin{array}{l}\text { a single electronic document flow within the digital } \\
\text { economy, a fully secure data transfer system, etc. }\end{array}$ \\
\hline Robotic data processing & $\begin{array}{l}\text { automated accounting information system, } \\
\text { Back-office "Button", etc. }\end{array}$ & robotic accounting information system \\
\hline Reporting and analytical & $\begin{array}{l}\text { automated accounting information system, } \\
\text { electronic document management }\end{array}$ & $\begin{array}{l}\text { a single electronic document flow within the digital } \\
\text { economy, a robotic accounting information system, } \\
\text { internal reporting patterns, easily configurable for } \\
\text { the specifics of the organization, etc. }\end{array}$ \\
\hline Account management & $\begin{array}{l}\text { production accounting with elements of } \\
\text { management accounting, decision support } \\
\text { system }\end{array}$ & $\begin{array}{l}\text { RPA (business process automation technology } \\
\text { based on the concept of software robots or artificial } \\
\text { intelligence workers), developed account } \\
\text { management }\end{array}$ \\
\hline
\end{tabular}

In 2013, the Agency for Strategic Initiatives, together with the Skolkovo School of Management, pointed out in the developed atlas of new professions some professional areas that will be in demand in 10-20 years, as well as professions that, according to forecasts of the compilers of the atlas, should disappear in the nearest future. The profession of an accountant is the first in the list of "endangered" in the atlas.

In 2016, Tatyana Nesterenko, First Deputy Minister of Finance of the Russian Federation, warned at the Moscow Financial Forum that "... the profession of an accountant, as it is, will increasingly leave the market. Keep in mind here, technology will just replace it".

In the presence of harsh remarks towards the withering away of the profession of an accountant, it should be noted the development of the professional standard "Accountant", which defines qualifications, i.e. knowledge, abilities, skills and work experience necessary for working as an accountant. Moreover, two positions of an accountant and chief accountant are identified in the professional standard. The main function of an accountant is the ability to perform the final generalization of the facts of economic life, while the chief accountant must be able to compile and present financial statements of an economic entity.

In 2015 the Ministry of Labor and Social Protection of the Russian Federation included the professions of an accountant, auditor and some other accounting and financial profiles in the list of new and promising professions in demand at the labor market.

In 2018, Olga Yeremeyeva, a scientist at Khakass State University, received a grant from the Russian Foundation for Basic Research in Economics to study accounting for future events in the modern information society. She notes that "... the profession of an accountant, of course, will not disappear, but the changes 
are large, and their pace is growing rapidly. Perhaps someday an accountant or accountant-operator will be a thing of the past. But the role of an accountant-analyst, a specialist who can form a professional judgment, on the contrary, will increase". The aim of the study is to establish the need and the possibility of accounting for future events in the modern information society.

This is a clear confirmation that the profession of an accountant does not die out, but evolves simultaneously with accounting.

Features of agriculture impose certain requirements on agricultural accountants:

- knowledge of the specifics of agricultural production, the principles of its organization;

- determining the cost structure and methods of calculating the cost of production;

- the formation of a wage system related to the volume and quality of work carried out, etc.

The knowledge, abilities and skills of an accountant in the field of information preparation and the development of management decisions conducive to business development come to the fore. At the same time, knowledge on organizing and maintaining accounting remains basic, they impose the ability to associate various costs with alternatives, identify limiting factors, and have the skills to develop not only pattern, but also original, non-typical management decisions.

In this regard, the profession of an accountant in the digital economy is transformed into an account manager (accountant, management). An account manager, in essence, is a manager who uses his professional experience in accounting as a means of achieving results, working with numbers as an information picture of production. A qualified account manager, as a member of the management team, coordinates the activities of structural units, taking into account the interests of each of them.

\section{Conclusion}

Summarizing the above, it should be mentioned that the digitalization of the economy, and in particular agriculture, is based on technical and technological components, which include the processing of global data through their digitization and storage. The digital economy is associated with improved agricultural production. The speed with which the digital economy is introduced into agriculture depends on the level of economic development, the level of education, the readiness of the regulatory framework, and the state of applied technologies.

Modern information accounting systems at this stage are the most digitalized element of agriculture, which require an appropriate level of training of specialists.
The analysis of the current situation on the labor market and employment in agriculture reflects the insufficient qualifications of accountants due to the low attractiveness of the industry, which complicates the digitalization of both agriculture and accounting.

However, the emerging transition to accounting robotics determines promising areas of development that contribute to its modern development, and as a result, a shift in emphasis from the traditional understanding of accounting towards account management and, as a result, the transformation of the accounting profession into an account manager. The role of an accountant in modern conditions expands accounting functions, including the development of managerial decisions aimed at improving the efficiency of the agricultural enterprise.

Thus, there is a transformation of accounting and the profession of an accountant in accordance with the needs of the digital society, which allows not losing the relevance of accounting and the profession of an accountant in the era of universal digitalization.

\section{References}

1. V.G. Khalin, G.V. Chernova, Digitalization and its impact on the Russian economy and society: advantages, challenges, threats and risks, Managem. Consult., 10(118), 46-63 (2018)

2. O.V. Chepik, G.V. Kalinina, I.V. Luchkova, On the issue of legal regulation of accounting in the Russian Federation, Financ. Econ., 5, 871-874 (2018).

3. Ya.V. Sokolov, V.Ya. Sokolov, Accounting history: textbook (MAGISTR, Moscow, 2011)

4. M.I. Stolbov, About some consequences of introducing blockchain in finance, Issues of Econ., 6, 133-145 (2018)

5. G.V. Kislyakov, N.A. Kislyakova, Management: basic terms and concepts: Dictionary (INFRA-M, Moscow, 2016)

6. V. Beattie, Accounting narratives and the narrative turn in accounting research: issues, theory, methodology, methods and a research framework, The British Account. Rev., 46(2), 111-134 (2014)

7. E.P. Polikarpova, I.E. Mizikovskiy, Preparing accounting information on costs for manufactured crop production, Custos e Agronegocio, 14(4), 149-166 (2018)

8. A.S. Zavgorodnyaya, I.G. Shashkova, V.S. Konkina et al., Adaptive Management of the Agricultural Enterprise in the Conditions of Environmental Uncertainty, J. of Advan. Res. in Dynam. and Control Syst., 7 (Special iss.), 2022-2031 (2018) 